\title{
Respiratory distress after total thyroidectomy
}

\author{
Teixeira J.C, Trabulo A., Pedroso V.M., Nunes L., Aquino E. \\ Centro Hospitalar de Lisboa Ocidental, Dept of Anaesthesiology, Lisboa, Portugal
}

\section{Introduction}

Bilateral recurrent laryngeal nerve (RLN) injury is a rare complication of thyroidectomy. Close post-operative care is recommended as airway obstruction may require emergent intervention. The authors present a case of bilateral vocal cord palsy.

\section{Case report}

\section{PRE-OPERATIVE ASSESSMIENT}

- 86 years old patient, female; for Total Thyroidectomy;

- ASA II;

- Neck TC: slight deviation of the trachea to the right without apparent compression;

- Videolaringoscopy shown no abnormalities.

\section{INTRA-OPERATIVE COURSE}

- General endovenous anaesthesia with orotracheal intubation; one attempt, atraumatic;

- The procedure was performed without complications;

- The patient was awake and transferred to the PostAnaesthesia Care Unit (PACU) after vocalization, eupnoeic and with saturation of $98 \%$.

\section{POST-OPERATIVE PERIOD:}

\section{POST ANESTHESIA CARE UNIT:}

- The patient presented temporary restlessness and stridor that disappear after calming the patient and breathing control. All monitorization was normal.

- Transferred to the ward asymptomatic after 24 hours.

\section{Discussion}

Thyroidectomy post-operative can be complicated with airway obstruction. Most frequent causes to be considered are:

- Hematoma with airway compression

- Laryngeal oedema;

- Hypocalcemia;

- Recurrent laringeal nerve (RLN) injury with bilateral vocal cord palsy;

- Tracheomalacia.

Bilateral RLN injury is rare $(0.4 \%)$ and nerve damage can be caused by nerve transection, ischemia, traction, thermal damage, hematoma compression or nerve oedema. Patients usually present with stridor, dyspnea and dysphonia but symptoms can be subtle as severity depend the type of lesion and the remaning vocal cords function and position

\section{Conclusion}

Patients submitted to a total thyroidectomy require close post-operative care. Airway obstruction due to bilateral RLN is rare but can present itself in an atypical way and cause life threatening events.

\section{References}

A. Christou N et al, Complications after total thyroidectomy. J Visc Surg. 2013:1-8.

B. Mattsson $\mathrm{P}$ et al, Recovery of laryngeal function after intraoperative injury to the recurrent laryngeal nerve. Gland Surg. 2015; 4(15):27-35

\section{WARD:}

- Continued stridor, respiratory distress, oxygen saturation $96 \%$

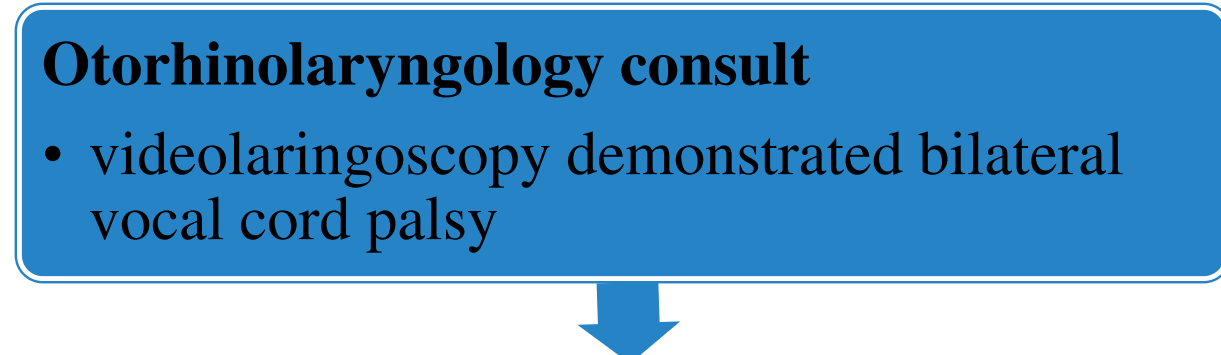

\section{Urgency tracheotomy performed}

Videolaringoscopy after 14 days

- Recovery of left vocal cord function

- De-cannulation

Discharged at 21th day pos-op
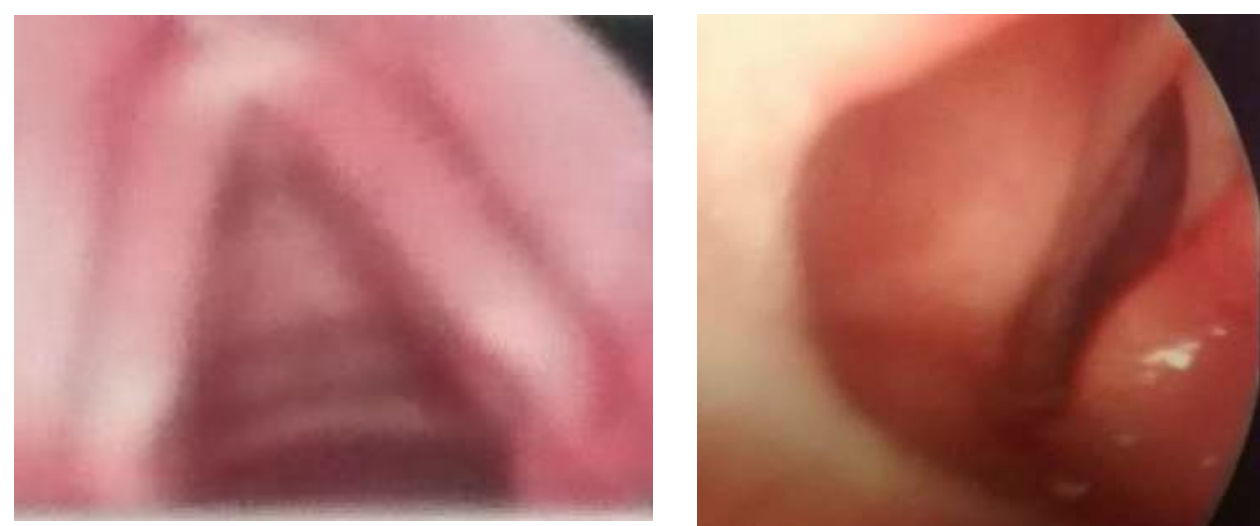

Pictures 1 and 2 . Pre-operative and at $14^{\text {th }}$ day post-operative videolaringoscopy images 